\title{
Dialogue
}

Our Own Liberation: Reflections on Hawaiian Epistemology

MANULANI ALULI MEYER

The Ocean Imaginary

SUBRAMANI

Responses

VILSONI HERENIKO, CAROLINE SINAVAIANA-GABBARD, AND DAVID WELCHMAN GEGEO

An Interview with Subramani

VILSONI HERENIKO

The Contemporary Pacific, Volume 13, Number 1, Spring 2001, 123-198

(C) 2001 by University of Hawai 'i Press 


\section{Our Own Liberation: Reflections on \\ Hawaiian Epistemology}

Manulani Aluli Meyer

I will no longer take anyone's word for my experience.

JAMES BALDWIN

W

hat a fascinating thing life is! I have survived the many, many stories of how I think, what I know, and who I am-all told by those who are well meaning, well dressed, and well ignorant of the deeper sides of my cultural epistemology. ${ }^{1}$ It's a telling that has captured more than my imagination-it has, instead, held me hostage to ideas and philosophies I have had no hand in forming, and thus I have felt no real stake in its potential to inspire.

It has been a confusing travelogue with regard to schooling and indigenous knowledge. I was and still am a back-seat passenger in this car called Education. I have sat like a good daughter on some long cross-continental haul, trying to behave, but because I have begun to question acultural and thus apolitical assumptions in the art of teaching and the science of learning, I am in essence changing my own destination. The hermeneutic hazing has begun. ${ }^{2}$ It is a strange world indeed, to wake up and realize that everything I have learned in school, everything I've read in books, every vocabulary test and jumping jack, every seating arrangement and response expectation-absolutely everything-has not been shaped by a Hawaiian mind.

Fashion yourself in this manner and you'll begin to see where the delay of our Hawaiian understanding exists-it is in our own understanding! We are still in the dungeons of standardized tests, intelligence quotients, classroom management techniques, homogeneous age groupings, and fifty-minute class periods. We still believe that literacy is the best indicator of intelligence. We are dulled by the guessing game of another culture. We are inspired by epistemological mediocrity. We are always at the short end of a smaller and smaller identity stick. Our biggest Hawaiian question this last 
century has been, How can we be more like them? has become slowly, Why do we want to be more like them? Someone has rolled down the window. The breeze of identity rushes toward my skin as the aroma of ocean air fills our memory.

It is more often the case that as we wake up and see strange vegetation from the back seat of our schooling car, we need only beg to pull over. Granted, we will be thrown out in the middle of nowhere, but as I have had this happen to me in my lifetime, I know I will survive and indeed, walk the highways with relief for the new adventure ahead, knowing that every step back is one step closer to my homeland.

\section{KNOWLEDGE AND IDENTITY}

But will it also be thought strange that education and knowledge of the world have enabled us to perceive that as a race we have some special mental and physical requirements not shared by the other races which have come among us? (Queen Lili'uokalani, I 898)

The truth is, Hawaiians were never like the people who colonized us. If we wish to understand what is unique and special about who we are as cultural people, we will see that our building blocks of understanding, our epistemology, and thus our empirical relationship to experience is fundamentally different. ${ }^{3}$ We simply see, hear, feel, taste, and smell the world differently. As I shall show in this essay, these differences are neither subtle nor imaginary, but large and enduring. It continues to amaze me that we have survived the carbon monocultural poisoning of our back-seat schooling vehicle.

Enter the discussion of epistemology. It is not a new discussion but because of the political times it has become the hotbed of academic discourse. It is the sword against anthropological arrogance and the shield against philosophical universalisms. How one knows, indeed, what one prioritizes with regard to this knowing, ends up being the stuffing of identity, the truth that links us to our distinct cosmologies, and the essence of who we are as Oceanic people. ${ }^{4}$ It is a discussion of place and genealogy. It is a way to navigate the shores of what is worth knowing and it is particularly important as we enter the new millennium where information will no longer be synonymous with knowledge, but rather how that information helps us maintain our sense of community in the daily chaos of access and information overload. 


\section{Our Ocean of Understanding}

Kal kaua sent him [grandpa] to England, and still he always said something nice to rocks. (Abraham Piianaia, 2I May I997)

Enter Hawaiian epistemology. Granted, it's a funny word and I'd like to pause to get the confusion out of our system, but we have to engage first with the Greek. I look forward to the day where we no longer use terms that compromise our identity. My M ori scholar and friend, Huia Jahnke, longs for the day we will all be describing our experiences in our own languages - and that day is coming; we must all first believe this. Hopefully the cost will not be the fracturing of our own communities-this continues to be a mistake here in Hawai'i. It is not the short term we look for as Hawaiians, it is the long. Anything else is a mistake pushed by minds that do not understand the essence of water or the finite nature of our human resources. It will always, always be a mistake to base a movement on money. Always. This is an epistemological point-that relationship is more valuable than the more modern sense of efficacy, money. Hawaiians know this, and as we struggle to see how best to be of use, we have only to relate hermeneutics to the equation to understand why and how things went wrong. But that's another story.

Hawaiian epistemology is a long-term idea that is both ancient and modern, central and marginalized. It is a distinct feature of our culture that cannot easily be distinguished from the fabric it is sewn into. It shifts, it is metamorphosed, it is changed by time and influence. It is constant. Here are just some ways to experience this ocean of knowing: ${ }^{5}$

- Spirituality and Knowing-the cultural contexts of knowledge

- That Which Feeds-physical place and knowing

- The Cultural Nature of the Senses-expanding the idea of empiricism

- Relationship and Knowledge-self through other

- Utility and Knowledge-ideas of wealth and usefulness

- Words and Knowledge-causality in language and thought

- The Body-Mind Question-illusions of separation

The following are ideas shared by twenty Hawaiian educational leaders. Their thoughts are the foundation for what I am beginning to know as Hawaiian epistemology. I offer it here to clarify the deeper struggle of how best to educate Native Hawaiians in our Americanized and capitalism-oriented society of Hawai'i. My understanding is specific to my place, space, and timing in this movement. It is my hope that it will inspire others as it does me. 


\section{Epistemological Theme i: Spirituality and Knowledge}

\section{The Cultural Contexts of Knowledge}

The learning apparatus is Lono and Kane. (Rubellite Kawena Johnson, I I April 1997)

Most of the Hawaiian educators I listened to spoke of where their inspiration of knowing something flowed from. This theme of spirituality was, by far, the largest of all seven categories. Inevitably, every mentor spoke of and lingered in this arena of how knowledge is affected, drawn from, and shaped by spiritual forces. These forces include environment, family members long passed, God, the many gods, and 'aum kua (ancestors).

"The domains of experience (body-centric) are conditioned by our relationship with gods. The spirituality and conduct between gods and humans is part of knowledge" (Rubellite Kawena Johnson, I I April 1997). This theme culls from rich and varied examples to substantiate spirituality as a "domain of experience" that validates and strengthens a cultural understanding of how we know and experience the world. Knowledge, for some mentors, became a sinew that ran throughout the ages, an extension of what is respected and what is practiced. It has an origin, and history helps direct its future. Most spoke of themselves as links in this chain of cultural continuity.

It extends all the way back to the beginning, so we remain connected. All the way back, and those spiritual forces are still with us! (Kekuni Blaisdell, 3 February 1997)

The question is, Who is the self? You're not just who you are now. You're aligned with people who have gone through it lots and lots of times. (Calvin Hoe, 28 May 1997)

I'm really deeply connected to my mother and ancestors and all the Hawaiians that came before us. And in me I have some of that cellular, molecular structure and memory of long ago. How comforting! (Ho'oipo DeCambra, 8 March 1997)

The "comfort" mentors spoke about describes what I define as a "cultural context" of knowledge. Knowledge has a genesis, it has a place of origin, and it has a specific decorating theme. Knowledge is shaped by what culture believes are "best practices." It is not something that is reinvented every generation. 
This knowledge-belief structure cannot possibly have a specific answer to how one approaches technology, for instance, but it sets the tone for how one handles technological influence and places it within a structure of values, priorities, and spiritual beliefs. This is not a discussion of narrowing worldviews, but of a specific cosmology that breathes in the many aromas of influence. This very hope of continuity brings about cultural morality, cultural practice, cultural epistemology. Mentors' belief that they are links in a Hawaiian chain reaching back to antiquity helps to prioritize how knowledge is acquired, exchanged, and valued.

[Knowledge] doesn't only have to do with intelligence, it has to do with spirituality, it has to do with everything that has lined up before you, and all of the things that are lined up ahead of you. All sorts of coming together to make all of this happen. You, yourself, cannot make any of this happen. (Pua Kanahele, I5 January 1997)

[Knowledge] has a future. What I do here, whatever knowledge I've gained here, or done here will follow after me. That's like immortality, you know. Knowledge is a sequence of immortality. (Sonny Kinney, 5 May 1997)

Knowledge as a "sequence of immortality" summarizes this sense of spiritual continuity, as does the notion that we, by ourselves, cannot bring about the kinds of knowing that endure. These are key images with regard to spirituality and epistemology because they draw from cultural beliefs about our place and purpose in the hierarchy of family, deified or mundane; our land, animistic or static; and our gods, plural or singular. It is an epistemological point because it helps formulate how we approach knowing.

\section{Epistemological Theme 2: That Which Feeds}

\section{Physical Place and Knowing}

I am shaped by my geography. (Hannah Kihalani Springer, I4 January 1997) Most prevalent in the interviews and also the most difficult to explain is the notion of ' ina, land.

'ina as origin, 'ina as mother, 'ina as inspiration. In this essay, 'ina refers to the environment. How this shapes how one experiences the world is an important lens through which to view cultural epistemology. It was the place of birth (" ina $b$ nau) where all mentors began their descriptions of who they were, and how it shaped their differences and values. It is where each one grew up that most shaped their worldview. 
Our cultural as well as physical geography is the foundation of our creativity, of our problem solving, of our knowledge building. (Hannah Kihalani Springer, I4 January 1997)

You can see in a person, if a person from $\mathrm{Ka}^{\mathrm{a}}$ or Kona, some people here in Hilo ... you can see the twinkle in their eyes [when they are speaking Hawaiian]. You can see a little laughter when they talk, but you go other places and you don't see that. You go Ni'ihau, altogether different, they laugh all the way right through! (Kamuela Kumukahi, 22 January 1997)

ina became an epistemological theme during specific interviews with mentors who kept drawing from their lands of origin or from their current work on lands that "feed" them. Here, "feeding" became both a literal and spiritual descriptor as mentors spoke of sustenance, growing knowledge, and inspiration with regard to ' ina. Land, sky, and ocean also became the classroom of their most vivid lessons, the home of metaphors that they continually draw on.

A person who has knowledge and information about Hawaiian practices, arts, skills and language, in my opinion, has something missing. They need the heart and the spirit of the Hawaiian in order to be Hawaiian. And the way that I view one developing the heart and the spirit of being Hawaiian is that one has to experience it. One has to take off all of [those] outer trappings and one has to be open to be bombarded by the environment, by the 'ina, by nature, and one has to be willing to delve into living an aspect of the way our forefathers lived in order to be able to get a glimpse of what it is to be Hawaiian. (Lynette Paglinawan, I February I997)

"Delving into living an aspect of the way of our forefathers" is synonymous with cultural practice. It is as most mentors reminded me: practice culture, experience culture, live culture. It is no longer enough to simply learn the history or language in an academic setting - one must teach how to fish in the language, how to weave lauhala (pandanus leaves) in the language, how to $m$ lama ' ina (take care of the land) via language. It is a call to practice. It is a reminder of the most important aspect of a Hawaiian knowledge structure: experience. "If you go down in Wai'anae side, you have to all sit there and listen. You have to listen for the pohaku [rock] to call you. You have to thank the ocean for helping farm it, you have to thank the rain, all those wonderful things. It brings you back to how wonderful our world is. You gotta be observant, you gotta have all the senses" (Gennie Kinney, 7 March 1997).

Here it is again, the connection land has with spiritual and religious 
structure. The specificity of such deities teaches us how to behave, how to enter the ocean, what to notice. This fact points, again, to epistemological origins tied to cosmology and ontological realities shaped by environment. It leads now into a discussion of expanding empiricism, the third epistemological thread.

\section{Epistemology Theme 3: Cultural Nature of the Senses}

\section{Expanding Notions of Empiricism}

I don't think I was taught that! I was hearing it. (Irmgard Aluli, 26 March I997)

Senses, a third Hawaiian epistemological theme, surfaced because one inevitably must discuss empiricism with regard to knowledge. ${ }^{6}$ Because of the fluid nature of each of the themes, this one in particular connected and ran throughout spirituality, place, and morality. It became evident from the discussions with the Hawaiian educators that senses are developed by culture.

Empirical beliefs were clearly detailed by Rubellite Kawena Johnson. In our interviews she outlined six "body-centric" notions relative to this discussion of how Hawaiians experience their world. These senses relied heavily on the fact and logic of our bodies. Further, because the nuance and metaphors of Hawaiian language are integral here, I humbly note my own inadequacies for translation and therefore deeper discourse. (It is my hope that future Hawaiian scholars head into this arena via Hawaiian language with a more mature understanding of its role in how Hawaiians shape epistemology.) The discussion of body-centric notions is basic to understanding the specificity of Hawaiian empiricism (table I). "Experience and moving into another realm of being [is valuable] because we don't believe the concrete world is the only reality" (Rubellite Kawena Johnson, II April I997).

The richness and importance of Hawaiian language situates this specific empirical system. The five "physical" senses: sight, taste, smell, hearing, and touch have direct parallels to learning, understanding, and knowledge. The sixth "sense" that Rubellite Johnson outlines, awareness, will be addressed later.

Each body-centric description links with how one engages in experiencing the world. It is obvious that Hawaiians shape an epistemology from predictable empirical sources. What is interesting with regard to this 
idea is how the specificity of culture informs how these empirical sources behave, both literally and metaphorically, in knowledge acquisition.

The fact that 'ike means "to see" and also "to know" shows how vision educates, how looking teaches, how watching informs. The importance of how we see the world cannot be overstated. How, then, is this "seeing" mediated via place, experience, and expectations of culture?

Table I. A Hawaiian View of Expanding Empiricism

\begin{tabular}{|c|c|c|c|}
\hline Sense & Description & Hawaiian Term & English Usage \\
\hline Sight & Ability to see & $\begin{array}{l}\text { 'ike (noun) } \\
k a \text { 'ike, ka 'ike 'ana, } \\
\text { ka 'ikena } \\
\text { 'ike (verb) } \\
\text { 'ike } \\
n n\end{array}$ & $\begin{array}{l}\text { to see } \\
\text { to know, to know by sight } \\
\text { to look at, to observe }\end{array}$ \\
\hline Taste & "taste" & 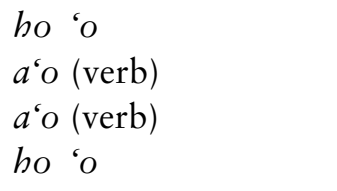 & $\begin{array}{l}\text { to try } \\
\text { to learn } \\
\text { to teach } \\
\text { to try to learn, to taste }\end{array}$ \\
\hline Smell & "breathe in" & $\begin{array}{l}i b u \\
\text { hanu } \\
b\end{array}$ & $\begin{array}{l}\text { nose } \\
\text { breathe in nose or mouth } \\
\text { breathe in through mouth }\end{array}$ \\
\hline Hearing & to hear & $\begin{array}{l}\text { lohe (verb) } \\
\text { lohena } \\
\text { ho'olohe } \\
\text { ho'olono }\end{array}$ & $\begin{array}{l}\text { to hear } \\
\text { what is heard } \\
\text { to pay attention, selectively } \\
\text { Lono is the god of sound }\end{array}$ \\
\hline Awareness & to touch & $\begin{array}{l}p \\
p \\
p \\
\text { 'apo } \\
\text { 'a'apo } \\
\text { 'a'apo kl keiki }\end{array}$ & $\begin{array}{l}\text { to touch with the hand } \\
\text { the "touch" of blowing wind } \\
\text { the touch, as light } \\
\text { to grasp with the hands } \\
\text { "grasping" with the mind } \\
\text { fast in learning, quick in } \\
\text { understanding } \\
\text { conditioned by intuition }\end{array}$ \\
\hline
\end{tabular}

Source: Rubellite Kawena Johnson, I I April 1997. 
She was doing stuff, she was doing this observation. I understand the concept of observation, but she was doing it. She talked about the difference between going to hula and doing hula. So, I say that my mom was engaged in the act of observation. She wasn't teaching me the theory that if you look out on to the landscape and if you know x, y, and z, you may infer a, b, c. She was doing it. (Hannah Kihalani Springer, I4 January 1997)

Thus enters the idea that our empirical rapport with the environment is not something passive. We are active in our understanding. We are engaged in it. Knowing something becomes something we create. "Understanding is something you cause. Ho'omaopopo, to cause understanding" (Rubellite Kawena Johnson, I I April I997).

It is like the word $a^{c} \mathrm{o}$, the word for teaching and learning. Even the sound of the word seems to infer reciprocity. It is also part of the word for "taste," as if "tasting" experience is a large part of understanding it. And $b$, the breath, the ritualizing of how a kumu (teacher) assures the continuity of knowledge.

When uncle Joe Ilala'ole used to teach aunty Emma, I would sometimes be niele, sit down and talk with him. I asked one day: "How did you get to do hula?" He told me stories, see? And that was by breathing into a person. I asked how? He told me, "My grandfather made me kneel by his side and he said, 'Open your mouth ... haaaaaaa'" [grandfather breathed into his grandson's mouth]. I don't know whether it was three times or five times. I forgot. (Irmgard Aluli, 26 March 1997)

Breathing into a chosen student's mouth is one way knowledge was given and is a metaphor for how Hawaiians engage in knowledge maintenance. It is deeply embedded in other, in elder, in spirit. It is linked with how Hawaiians view teachers, words, timing, and experience. This point will be further developed in the sixth epistemological theme-words and knowledge.

Listening, too, becomes something that is lifted beyond the mundane. To pay attention, to really listen (ho'olono) is to invoke a spirit, a deity. Listening, then, becomes a spiritual act. Doing it well is tied to what Pua Kanahele said to us earlier, "You, yourself, cannot make any of this happen." It is intimately tied to other and to how we invoke our own genealogy to learn what is most critical. Listening well is found in the act of focus, and focusing is part of what culture helps to define.

They tell you one time, you know Hawaiian style before ... Hawaiians don't like to repeat, when they tell you to do something. First, they're going to show you what to do. It's up to you to look and to do what they did. They going to 
show you what to do. It's up to you to do what they did. They are not going to repeat it back to you. So, I guess we learned more by observation. We hardly asked questions because we should be smart enough, one time they tell us, so it's just like, intuition, you know? Because Hawaiians don't like to repeat and repeat, then they call you $h p$, where you should be intelligent enough to know. (Florence Like Kumukahi, 2I January 1997)

You know what they used to say to me, and I'll never forget, that's what I taught my children: $n n$ pono ka maka, ho'olohe pono ka pepeiao, pa'a kou waha, hana ka lima. That's a famous saying from my po'e $k$ puna [elders]. Be very observant and when you are to listen, listen very carefully, but whenever you listen, that's not for you to open your mouth and create problems, that's why they say, shut your mouth and work, do the work. (Abbie Napeahi, 20 January 1997)

Finally, we have touch- 'a'apo. Consider how the sense of touch informs our understanding, particularly when we "grasp" something. We can know through our bodies, our bodies become instruments of knowing, and instruments for cultural expression.

Because the fundamental building block of knowledge, empiricism, stems from how we engage in the world, it must now be defined in specific, contextual terms. Even touching does not escape the influence of culture. Knowledge, then, is something we cause. Touching, grasping, understanding-all lead back into the discussion of experience and awareness.

The linking of experience with awareness is active. For example, surfing affects our knowledge about the ocean, and dreams affect our relationship to reality. The honor we hold for our kumu, our teachers, affects how we listen. If paying attention also invokes the god Lono, how does this affect our choice of what to share and when? While the genesis of Hawaiian knowledge is based on experience, and experience is grounded in our sensory rapport, how then do these senses themselves shape our knowing? "Everything is alive! You see that reflection of the sun? That's alive! It's saying something, it's sending a message! And we need to be able to receive and process that message and think and act accordingly" (Kekuni Blaisdell, 3 February I997).

How does one understand physical cues to "act accordingly"? Perhaps this leads into the sixth body-centric empirical notion of Rubellite Johnson's-awareness. How we become aware of the world is an accumulation of sensual maturity, but what events then become the signposts for how this "awareness" gets developed? How does culture shape this? Many mentors described vivid and clear ways Hawaiian systems and values developed their awareness, intuition, insight, and what they knew. "I think 
the basic idea of ancestral prompting is not $n a^{\prime} a u$, but awareness. You become aware of something initially and you can either pay attention to it or you can just discard it. Anyway, that very first feeling, my mother always said, 'Pay attention to it, then see where it goes, but pay attention to it, it needs to be there and it's telling you [something]'” (Pua Kanahele, I5 January 1997).

The art of paying attention is indeed a culturally specific "deep internalized knowledge." It is shaped by a culture with a particular moral posture and achieved only through practice. Awareness, the "sixth sense" described by Rubellite Kawena Johnson, is a valuable example of the active role Hawaiians had and currently have with knowledge creation.

\section{Epistemology Theme 4: Relationship and Knowledge}

\section{Notions of Self Through Other}

How can you be happy in your experiences when others are unhappy? (Gladys Brandt, 27 March 1997)

Relationship as the "cornerstone of Hawaiian experience which shaped knowledge" is also a key component for all Hawaiian educators. They acknowledged the idea that relationships mattered in profound ways. Relationships or interdependence offered Hawaiians opportunities to practice reciprocity, exhibit balance, develop harmony with land, and generosity with others. Mentors described the vital force of relationship in myriad forms and with clear vocabulary and imagery.

We had three houses on this one lot and they were all family, and there were all these kids. I thought my cousins were my brothers and sisters, but they was really my cousins. I thought my brother was my uncle, but that was really my brother (laughter!). It was just because we had all these extended people around, it was a lot to make sense of who was who. There was no way to distinguish. There were no strangers. (Ho'oipo DeCambra, 8 March I997)

Here it is again, this continuum with our 'ohana, except in this theme, the focus is now on "other" and how maintenance of relationships takes conscious and deliberate thought and action. Knowledge is the by-product of dialogue, or of something exchanged with others. Knowledge, for some mentors, is a gift that occurs when one is in balance with another. "Knowledge is something that is kept for you" (Keikialoha Kekipi, 7 May I997).

For Keikialoha Kekipi, knowledge is considered a gift and a responsi- 
bility. What is key, then, for his intellectual advancement is his continued rapport with those who "keep" knowledge for him. These are his $k$ puna and the "ina on which he resides and works. Relationship, with those living and dead, directs this essay toward an expanding empirical sense. Culturally formed sensuality and its link with relationship was a substantial idea for Hawaiian epistemology that surfaced in many interviews. It prioritizes family, reciprocity, experience, and the diversity of the ways one is educated.

My world was shaped through my contact with the people that I lived with, my relatives. (Lynette Paglinawan, I February 1997)

You don't overstep someone you think who is older than you in authority.You don't try to correct. You pay homage to the old all the time, bow to them. They are smarter than you; they've lived longer; take their word rather than mine. I may disagree, but you listen to that. (Irmgard Aluli, 26 March 1997)

Having good rapport and listening to one's elders is not new and revelatory. It is how that rapport is sustained and the extent of its importance that is unique to Hawaiians. The fact that every educator spoke in relationship terms highlights the importance of knowledge that is shaped by such a priority. It is evident when discussions turned to issues of validation, responsibility, and humility that morality, again, crafted relationship.

Thinking is also having others tell you what they think. (Abraham Piianaia, 2I May 1997)

The validation by others only enhances the mana that is there. The value of that tradition lies within itself, and the results of the use of that practice of that tradition is the validation, but the mana is further enhanced as others begin to recognize the value. (Lynette Paglinawan, I February 1997)

The practice of interdependence was not at the loss of one's self or individuality. These concepts were simply not mentioned. Here is where notions of Hawaiian epistemology substantiate a well-defined framework of community and family dependence. The defining of how one's context shapes experience and how those experiences shape understanding now becomes clear. It is at the heart of what it means to know something in a Hawaiian worldview. It is in the "being."

So, assuming responsibility for one another also helps us be pono. (Likeke Paglinawan, I February I997) 
My mother and father gave me the importance of family, of working together, of one's responsibility to each other. That was key. (Keola Lake, 26 January 1997)

Humility is valuable, very valuable. You never put yourself up, you know. (Irmgard Aluli, 26 March 1997)

Responsibility for others, allowing your thinking to be validated by others, and seeing yourself through the lens of "other" is sometimes antagonistic to a modern system of social mores. A few mentors spoke thus in bicultural terms. "Your uncles and aunts are your other parents and they have just as much responsibility in raising you and therefore your reaction to them and responsibility to them, and at the same time you're being inbred by western thought because you're American, you're growing up American at the same time, so you have these two ongoing, sometimes, conflict" (Keola Lake, 26 January I997).

This idea, that there are multiple realities of living in society, found expression in many interviews. One of the most striking comments shared by mentors about knowledge, knowing something, and relationship was expressed by Uncle Kamuela Kumukahi when he described his childhood days in rural $\mathrm{Ka}^{6}$.

When I can take care of the family, when I go fishing, I think I'm getting good; I'm not good yet, but I'm getting good. When I come to a point where I can study, oh, it's gonna be windy today, where I can see before time, beforehand, then I know I getting little bit better. Then, when I go up and go out and harvest the fish or crabbing or whatever, if I get my share then to satisfy the family; how many meals we can have, then I know I can take care. Then I know something. (Kamuela Kumukahi, 22 January 1997)

Kamuela Kumukahi knows something when he can feed his family. It is the logical result of practice, observation, awareness, and morality. Feeding family becomes the place where practice dovetails with intelligence and compassion.

What was interesting about Kamuela Kumukahi's response was the fact that it answered the question, How do you know you know something? His answer, "Because I can feed my family" pushed something potentially abstract and academic toward the center of what really mattered with regard to knowing something. One could easily argue that working as an accountant also feeds family, but it was his quickness of response, his sincerity of imagery, the priority of relationship, and many more nuances that 
helped remind me how and why this perspective is culture specific. It was inherently tied to its utility and rooted in the personal. He also reminded me that knowledge is valued when it is applied.

\section{Epistemology Theme 5: Utility and Knowledge}

\section{Ideas of Wealth and Usefulness}

Going to the beach to her [mother] was a place where you would go and gather and not a place for recreation. (Pua Kanahele, I 5 January 1997)

Purpose and function are tied to knowledge. Most Hawaiian educators spoke in clear terms with regard to how information that did not have use could not become knowledge-it was simply information.

Mentors did not boil down this focus into a discussion of vocational learning or learning styles. It became, instead, a rich and contextual look at a philosophy of aesthetics and epistemology that placed utility, spirituality, and context at the core of what it meant to be aware, to engage in things of purpose, and to be shaped by what is meaningful.

Wasted knowledge is a frivolous kind of thing. There are frivolous things, like, I think all of these talk shows for instance, are frivolous knowledge, [they have] no meaning. (Sonny Kinney, 5 May 1997)

Huli ka lima $i$ luna, make 'oe; huli ka lima i lalo, ola 'oe [Turn the hands upward, you die; turn the hands downward (work) you live]. This is our famous saying all the time, all the time ... from as far back as I know. (Abbie Napeahi, 20 January 1997)

They have to experience it, and sometimes you see somebody who's gathering all of this information kind of already beginning to understand it, which means he's more in tune with what this information is all about, whether he has had experience in this or whether there is an alignment coming together of ancestral memory making him aware of it, you know; it's not known until a little bit farther, but what he does with it is, to me, the real test of intelligence, how he treats it and whether it becomes functional for him, not only cerebrally, but also functional for him in everyday life. (Pua Kanahele, I 5 January I997)

The idea of "function" was important to many mentors. In this way, all facets of the environment and every relationship became potential sites of function. Of course, this too is shaped by morality, by history, by genealogy, and by one's belief in continuity. 
How do I know I know it? Repetition is one, utilization is another. You know if it can function, it has a function and you've proven that with knowledge you can make it function, so, there's repetition, there's utilization, there's history. Once you know something, you'll have a historical knowledge of where that is and where that went, the origin or whatever, so there's a history of how that knowledge came to you. There's also something important that has to do with what you can pass on. If you know what it is, you can pass it on, if you don't know, you've got nothing to pass on. (Sonny Kinney, 5 May 1997)

And so purpose can be defined by what is worth "passing on." The link with history again helps to define what is worth repeating. Knowing history, knowing culture becomes part of what is considered "best practices."

We'd go up to the mountains so I write about the mountains. I love ginger, we pick ginger, we make leis, ginger coming to my songs. It's all from experience [knowledge] and you apply it later on in your music, or in your poetry. (Irmgard Aluli, 26 March 1997)

Function is tied to lifestyle, and so you have to be able to use it in your lifestyle, it has to be tied to family, it has to be tied to land and it has to be tied to establishing the foundation. (Pua Kanahele, I5 January 1997)

The "foundation" Pua Kanahele spoke of refers to how one strengthens family traditions, beliefs, and practices. For Irmgard Aluli, this translates into extending her family's talents and mana (spiritual gifts) with regard to music, composition, and performance. She gathers imagery and experiences for her music in the mountains, she cultivates rapport and inspiration from the images around her. She finds "use" in what is beautiful. This point does not belittle notions of aesthetic appreciation, rather it brings beauty into the realm of utilitarian expectation, which is shaped by cultural nuance and needs. "I try to do things purposefully. No more enough time to do things unpurposefully" (Calvin Hoe, 28 May 1997).

Mentors spoke about naming children, knowing the environment, and understanding why places were named certain ways. They spoke in terms of function and purpose and did not separate intelligence from practice.

A lot of things are functional. You know you know because you can accomplish it. (Calvin Hoe, 28 May 1997)

If I teach a chant just to be teaching a chant, then that's kinda abstract to me. If I'm going to teach a chant because we're going to do ceremony with this chant, then that's functional, that's more lifestyle, but this other way where I have a class of chanting, to me that's like the education system, that's not functional. (Pua Kanahele, I5 January I997) 
The doing, the cultivating, the accomplishing-all verbs to describe how these Hawaiian educators maintain and advance what is worth knowing to them. It is a basic point in this discussion of epistemology to highlight ideas of purpose, function, and use. This point was found in many interviews and descriptions of how mentors chose what was worth practicing.

Meaning is tied to what we did, it was something we could use, something that was necessary for us, something that would give us a livelihood. (Ed Kanahele, I5 January 1997)

What you have is yours and so you need to keep it, you need to make it grow, that's what you inherited and so it belongs to you, therefore, you need to cultivate it. (Pua Kanahele, I5 January 1997)

Utilitarian expectations extend culture and strengthen family. The belief that meaning is tied to learning was not something hidden or subtle for the twenty Hawaiian mentors. It is a pivotal hope for the why, how, where, and what of lessons, understanding, and the creation of a meaningful life.

\section{Epistemology Theme 6: Words And Knowledge}

\section{Causality in Language}

You cannot curse people. You curse people, it hits those people, so you have to be careful about what you say, until today. That's why we're so careful not to curse anybody. (Florence Like Kumukahi, 2I January 1997)

The idea that words cause things to happen was not a salient notion in the interviews with our Hawaiian educators. Some, however, spoke about how important it was to listen and not talk, and another believed that the most intelligent person in a meeting was the individual who spoke the least (Abraham Piianaia). I found the absence of information for this category fascinating and wondered if I missed subtle nuances a theme like this evoked. (Themes were developed from a preliminary review of literature.) Mostly, those who did talk about the importance of words and their link with knowledge did so indirectly.

Knowledgeable [is] knowing when to share and with whom to share-I think so. You don't just give to anybody. Teaching carefully for ones that you choose. (Irmgard Aluli, I6 March 1997)

In order for us to know, we don't accept whatever is told to us, and we're told that's the ho'op $p$, that's the challenging. I always use this expression in hula. 
"Okay, I dare you to dance!" That's the old saying, 'a'a ka hula, e waibo $i$ ka hale. I dare you to dance or stay home. There's a wealth of things. We have a respect for elders, we have a respect for places they are, but our elders have also challenged us in the past as we grow up to meet the rigors of living, that at a particular point, don't accept everything. (Keola Lake, 26 January 1997)

Here, hermeneutics helps to explain why it matters that the knowing who is talking and how what's being said gets incorporated into what is learned, or if it gets taught at all. And so, context plays another role when words, "dares," and lessons are shared. And of course, context is culturally situated.

In one particular interview, however, the idea of words and causality were clearly defined. Florence Like Kumukahi gave a vivid story of how words linked with causality, and it serves as one example for this category.

We were always told, you put plenty love into it. Don't grumble, you're doing it with love, your kankan [meal] will come out delicious, but if you grumble, then everything will sour, you know? Okay, you give an assignment to a family. Maybe that family you'd say: "You cook the long rice and chicken." Come that night it starts to bubble, then you would know they grumbled, they didn't put their heart and soul in making this, so you can find out who grumbled, I mean, by the taste. (Florence Like Kumukahi, 2I January 1997)

This epistemological category expressed itself more clearly in how words and speaking were expressed. Some mentors spoke of having practiced the art of word crafting and how this, too, played a part in the timing and exchange of knowledge.

I best learned from the elders including my parents. As I was growing up, again, they were my first teachers. Among this group, it wasn't that children should be seen and not heard, we were welcome to be heard but best we be engaging, best we be entertaining and accurate in what we had to share with them so exchange was welcomed and encouraged and so was the integrity of that exchange. (Hannah Kihalani Springer, I4 January I997)

I was taught as a child: "Don't accept everything as being copacetic; there's a time for you to ho 'op $p$. If you no like, tell us!" (Keola Lake, I6 January I997)

And so mentors acknowledged the weight of words and recognized the importance of speaking out when appropriate. It was not, however, an important facet in the overall discussions. I believe the emphasis on experience placed the spotlight on quality, physical engagement, and that, perhaps, in deeper conversations the mentors would speak of the subtleties 
of how words and their parsimonious distribution may have played a role in shaping their experiences.

\section{Epistemology Theme 7: The Body-Mind Question}

\section{The Illusion of Separation}

Liver is where you digest the powers of perception. Digestion is not purely physical. I have "fed" on knowledge. It is an internal digestion. If I have digested a book, I've eaten it, digested it. This is where we separate epistemologies-in digestion and the vital organs. (Rubellite Kawena Johnson, II April 1997)

The separation of mind from body is not found in a Hawaiian worldview. Intelligence, for these twenty Hawaiian educators, was not separate from feeling. Indeed, intelligence is found in the core of our body system-in our viscera, the na'au. For mentors it is the feeling of something that constitutes part of knowing something.

You bring your na'au right there, and when you know you know something, you feel it over here [points to stomach]. You know you know it. (Gennie Kinney, 7 March 1997)

That's another way, to me, of knowing something is that you've been told by an influence that you cannot see, but you can feel inside as well as outside, that the place is not good for you, and so I have to pay attention to that kind of thing ... so, that's one way of knowing, so you have to pay attention to your na'au. (Pua Kanahele, I 5 January 1997)

Actually, some of the na'anao is already inside you. You born with it. Sometimes, and they call it common sense; sometimes your common sense is more better than the education, see? (Abbie Napeahi, 20 January 1997)

I know something when my imu [slang for stomach] is lit up. (Keikialoha Kekipi, 7 May 1997)

The idea of "comfort" is part of this discussion of intelligence, as if knowing something had to be embedded in feeling that it was okay. This is where mentors spoke in graphic and simple terms. If it did not feel right, it was not proper to proceed, or that knowledge was something to cast aside. Thus extends the discussion of how culture shapes sensory cues and how these cues shape how mentors develop rapport within their world.

I know something when I feel comfortable. You feel things. Keep your senses open. Remember, how you feel about something-if it feels right. (Calvin Hoe, 28 May 1997) 
Feeling, the definition of feeling for me has to do with whether or not I feel okay, whether or not I feel comfortable, whether or not I am not out of sorts. It has to do with not feeling anxious, it has to do with not feeling scared; it has to do with not being uncertain like I have to look over and check myself time and time again. It's a coming together of knowledge and emotion in my gut when it merges, and I'm altogether comfortable. (Lynette Paglinawan, I February 1997)

When I feel comfortable with the idea of the issue, I have a greater understanding. (Gennie Kinney, 7 March I997)

Feeling comfortable is part of Hawaiian intelligence. Mentors mostly used the idea of emotions and feelings interchangeably. However, Pua and Ed Kanahele drew a distinction between feeling and emotion that offered a valuable insight. It put in relief how "feeling" shapes the process and product of knowledge production, and whether it was innate (feeling), or learned (emotion).

I don't divorce myself from feeling and knowing something. Feeling and knowing go together. Emotion, on the other hand is a different thing. You can get angry, glad, happy, euphoric, whatever other kind of emotional words you want to use, but in a situation of knowing something, feelings come into play. (Ed Kanahele, I5 January I997)

Feeling, to me, for most people, has to do with emotion. This other feeling that I'm talking about does not have to do with emotion. It's . . . instinctive. You know, like a pig knows when it's going to storm or a dog knows when there's going to be an earthquake; it's instinctive, and then we reach to it, and so this feeling I'm talking about is that kind of instinct. It doesn't have to do with emotion. (Pua Kanahele, I5 January I997)

Feeling something was not strictly emotional. For the Kanaheles feelings reflected an instinctual sense. This distinction fine-tunes how feelings shape epistemology and brings us back into our senses, our "basic perceptions," and how they shape how and what we know. Knowledge is not carved from anger or joy. Knowing something is feeling something, and it is at the core of our embodied knowledge system. Knowing something, however, is metaphorically housed in our stomach region because that is also the site of our emotions, our wisdom, as if knowledge also shapes how we emote. Perhaps then, feelings precede emotions, then wisdom develops.

The question then arises: Why the stomach? Why not the brain? Why is intelligence housed in the viscera of a body system? These questions were approached and answered by some mentors in profound ways. 
Brain is the seat of power, liver is the seat of intelligence. (Rubellite Kawena Johnson, I I April I997)

The typical approach: “There's a simple explanation for that." Things react and cause another reaction, etc. To a certain extent that's correct. And that's why Hawaiians refer to our innocence of intelligence as $n a^{\prime} a u$, rather than brain, primarily because physiologically our brain is known as lolo, and our heart and our intestines are referred to as na'au. But when we talk about intelligence, which has all the senses of perception, it comes from the na'au, the inside. Everything that is logic says, "that doesn't make sense," so the Hawaiians said we have to act on both, with the combination where the two must be in pulse. Without heart we don't have sense! (Keola Lake, 26 January I997)

There are things that have happened to me that are very meaningful and deep. And, in the process of having what is here [points to head] merge with here [points to stomach area], before it comes together, there have been times when I've questioned and I've said "show me the way, give me a sign," because I'm headed in that direction. "Is this the right way?" And then I see a sign [claps hands]. That's it! If I travel that path again, I don't need the sign, I know it's right. (Lynette Paglinawan, I February 1997)

The merging together of "head and heart," the dual system of knowing is akin to acknowledging that information and conscious practice are fundamental to common sense. As Keola Lake reminded us: "Without heart we have no sense." How this remains specific to a Hawaiian worldview is that the $n a^{\prime} a u$ is also considered the heart. It also is the place of wisdom. This point was touched upon by many mentors.

For me, the $n a^{6} a u$ is gut feeling. $\mathrm{Na}^{\mathrm{a}} \mathrm{a} u$ and when you put [the letters] a-o, na'anao [learned, enlightened, intelligent, wise], okay, that's knowledge. It's connecting you to your knowledge as up here [in] your head, because your feelings start from gut, here, then it comes up here. That's the Hawaiian way of interpretation. When you get that na'au, you know when you get that feeling, gut feelings, that you want to do it, you're gonna do it, it's not only slang, it is real. And then you feel the power, you know, the mana is with you, you get that feeling coming from here and coming up and coming out, see? It has to start coming from here [points to stomach]. (Abbie Napeahi, 20 January 1997)

Learning-when we talk about comprehension: comprehension deals with two levels - the intellect and the gut, the emotion. And if information is available only here [points to the head] but you lack information here [points to stomach] because you don't have the experience, then you don't have full comprehension, you're only dealing with one level. So, for me, getting infor- 
mation from out here deals with the intellect. I want to feel it. I want to experience it in its many shades and shapes and sizes, and then I have a depth to this one-dimensional data with the feeling and the experiencing it. Then I give it a body and I give it a shape and I give it a personality. That fills it out for me; that for me, is comprehension. When I'm able to do that, I'm able to transfer this idea into different arenas. (Lynette Paglinawan, I February 1997)

Lynette Paglinawan defined a kind of intellectual triangulation for comprehension-through information, experience, and feelings. All three descriptors are sprinkled throughout this theme as vital components to knowing. Her message is subtle, profound, and transcends simple dualities and obvious dichotomies with regard to mind and body. Consider, again, the idea of na'auao (enlightened stomach).

But that's what na'anao is. It's a cosmic center point. It has to do with your ancestors coming together with you. It has to do with your spiritual being coming together, it has to do with our physical being. (Pua Kanahele, I 5 January I997)

Sometimes we are so sophisticated in our intelligence that we miss the bottom line. We miss the basic sense, the basic perception. So, understanding the $n a^{\prime} a u$ is the best way of making sense of our way of intelligence, as opposed to ignorance. Na'auao when there's a brightness. Indigenous people are much closer to things that are relevant. They lived and absorbed and exist[ed] by the environment and all the grandeur of size and everything else. We just become one small incident in a mass of things. We have to, if we are part of this other thing that is animate or inanimate, function in that world of things that are created, and we have a place. And if we believe this very simplistic idea that all things exist, animate and inanimate, we should have respect for all things. And as simplistic as we should respect all things, then we should be in balance with the things that are existing. (Keola Lake, 26 January 1997)

Understanding how viscera connects to intelligence perhaps brings us back to "the cosmic center point" of how and when knowledge is experienced. It is a clear plain from which to view the many ways people judge intelligence, understanding, and knowledge.

This discussion of $n a^{\prime} a u$ and na'auao is an intimate look into core Hawaiian beliefs that strongly identify with the idea of embodied knowing. It is "knowing" that is not divorced from awareness, from body, from spirit, from place. These descriptors personify what was most obvious to the mentors with regard to epistemology. $\mathrm{Na}^{\prime} \mathrm{au}$ and $n a^{\prime}$ auao are complex ontological descriptors that fuse with all other epistemological themes and 
threads. They highlight the idea that cultural views of where intelligence is "housed" are also part of how intelligence is received. These emic terms reflect the spiritual, relationary, utilitarian, and moral pathways knowledge takes to get to a Hawaiian psyche. It is best described by kumu hula Pua Kanahele.

$\mathrm{Na}^{\prime} \mathrm{a} u$ is the center of who you are. $N a^{\prime} a u$ is the center of your body, the center of your poles between your very spiritual and your very earthy, or your very airy and your very earthy, and it's that center pole. I think when your whole body or when your whole self reacts to something it all comes to that center. If it doesn't react to it, then one part or the other parts, if you're looking at something at a different level of intelligence, what you're doing is really working up here [points to head], you don't feel anything down here [points to $n a^{\prime} a u$ ] but it's something that has to do with intelligence, but if it's something that you can react to and if it's something you seem to understand from either your childhood or from your growing up days, and right away you can relate to that thing. All of that comes to center, so you can pull everything together and it centers ... that's na'au, na'auao. To me, na'auao is when everything, not when you, but when everything kind of centers for you and then a light comes on, and then you can relate to it, that's na'auao. It's understanding it at many different levels, not only with the level of intelligence, of thinking about it, but the level of practicum, of having done it somewhere, understanding how it works, understanding why it works. To me that's na'auao. It's being centered, it's when everything comes together. (Pua Kanahele, I 5 January 1997)

$N a^{\prime} a u$ and na'auao help clarify the union mind has with body and body has with spiritual forces. It is the A BC of formulating a Hawaiian epistemological vocabulary that now has been shaped by the insights of these twenty Hawaiian educators.

\section{Ha'ina Mai Ka Puana: The Story Is Told}

Ke noho $k$ ua i ka m lie a ho'olohe in 'ike a tupuna $m$, he beauty ho' $i$ kau. When you and I sit in serenity, and tune in to the endless knowledge of our ancestors, it is a beautiful enlightenment beyond comparison. (Aunty Malia Craver, I I November 1994)

So here we are. We have stepped from the schooling vehicle that dismisses the idea that empiricism is culturally defined. We are walking toward the ocean again. How intelligence is viewed and respected can eventually return into our own minds as Native Hawaiians. Will we now develop a 
standardizing philosophy or step beyond the potential neocolonial trap of "universalism"? It has still to be seen. There are signs of the struggle everywhere in our Hawaiian communities. Exciting movements are found on every island, particularly since the Hawai'i legislature passed Senate Bill 62 in 1999, which allows for twenty-five charter schools in Hawai'i. It is an unusal movement that finds rural and urban Hawai' $\mathrm{i}$, from $\mathrm{Ni}^{\prime}$ ihau to South Kona, complete with community, family members, and educators taking hold of their resources to help heal and educate our youth. Currently there are fourteen Hawaiian language and cultural charter schools struggling to open by the fall of $200 \mathrm{I}$. We are beginning to understand that Hawaiian education is not something in relation to a western norm, but something we must define in relation to our own understanding of ourselves, our past, and our potential. It is something more organic, more real, more tied to place. It is something that the Hawai'i Island Native Hawaiian Education Council members saw one unforgettable afternoon, almost without effort: "Native Hawaiian Education is more often experienced as community-based projects that are culturally driven" (Hawai'i Island Council Report to the Native Hawaiian Education Council, August I997, 4).

There it is. How do we educate our youth for the challenges of the next millennium? We surround them with our community, we give them meaningful experiences that highlight their ability to be responsible, intelligent, and kind. We watch for their gifts, we shape assessment to reflect mastery that is accomplished in real time, not false. We laugh more, plant everything, and harvest the hope of aloha. We help each other, we listen more, we trust in one another again. We find our Hawaiian essence reflected in both process and product of our efforts. That is Hawaiian education, and understanding our Hawaiian epistemology is our foundation, our kumu$p a^{\prime} a$. So, let it be said and let it be known: We have what we need. We are who we need.

\section{Notes}

I Epistemology is the philosophy of knowledge. It is a way of asking the questions, What is knowledge, How do we know, What is worth knowing? It is another way of saying "Indigenous ways of knowing." I use epistemology instead of "Hawaiian ways of knowing" because it is a word and idea that barters within the currency of mainstream academia. I am conscious of using such terminology until our language has its own term, and I work daily for this to occur. 
2 A philosopher-farmer, Jimmy Nani'ole, speaks of only hermeneutics. He sees this as the foundational idea of all that we must look into. Hermeneutics asks the questions, Who is speaking, What is both the unconscious and conscious intention given that information, and Who is the audience? The same questions can be applied to texts, ideas, essays, curriculum, pedagogical expectations, and so on. Everything can be scrutinized in this way, as I show in this essay. Much can be understood if one looks deeper into the who, why, how, and what one speaks. If epistemology is the shore-break, hermeneutics is the deep ocean.

3 Empiricism claims that all knowledge is derived from experience and that this experience is a product of our five senses: hearing, sight, taste, smell, and touch. I believe that a farmer from Iowa will have an empirical understanding of his cornfield that is far different from mine, a girl born on the shores of $\mathrm{M}$ kapu. The fundamental notion that our very senses are culturally educated has become the "situational" and "relativistic" argument in philosophy, and because of this, the universalizing of Hawaiian epistemology is not possible.

$4 \mathrm{I}$ am indebted to the brilliant visionary and writer, Epeli Hau'ofa, who helped me understand that we in Hawai' $i$ are not living in the most "isolated land mass in the universe" but rather, in one of the most interconnected lands in the world. Ocean connects us. Ocean is in us. We are Oceanic people. It was a liberating idea that continues to inspire me. Mahalo, Epeli.

5 The following discussion is a summary of chapter 4 of my thesis, "Native Hawaiian Epistemology: Contemporary Narratives," I998. That chapter summarized the findings of the twenty interviews I conducted over a one-year period with Hawaiian educational leaders on the islands of Hawai'i and $\mathrm{O}^{\prime}$ ahu. I refer to these informants as mentors because that is how I experienced them.

6 Empiricism is the philosophical belief that all knowledge comes from experience and that experience is shaped by our five senses. I believe that if our senses are culturally shaped, then empiricism, itself, is a cultural notion shaped by environment, mores, values, cosmology.

\section{Abstract}

As the Hawaiian political and cultural movement continues to grow, issues of representation, power, and control are being critiqued-now by Hawaiian minds. In this essay I look at the fundamentals of Hawaiian epistemology and begin to link them with the educational reform now underway in Hawai' $i$. With the guidance of twenty mentors, I outline seven epistemological categories that begin to solidify a distinct way in which to view teaching, learning, intellect, and rigor. These categories, now struggling to be useful in the Hawaiian Charter School movement, will inevitably also serve as a way to critique the current colonial system in 
Hawaiian language immersion, spotlight the oppression embedded in well-meant content and performance standards, and highlight the hidden curriculum of assimilation and the acultural assumptions in pedagogy that exist in Hawai'i's colonial schools. This outline of a Hawaiian philosophy of knowledge expands, invigorates, and redefines ideas of empiricism, intellectual rigor, and knowledge priorities-all through Hawaiian ontological lenses. Like any definition of culture put forth by indigenous practitioners and scholars, it pushes the envelope of what it means to think, exist, and struggle as a nonmainstream "other," and as it details the liberation found in identity, it must also, inevitably, outline the systems that deter its full blossoming.

KEYWORDS: culture, empiricism, epistemology, Hawaiian, intellectual, ontology, philosophy 